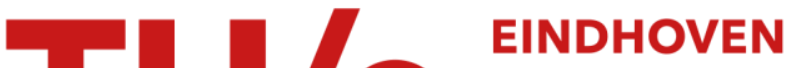 UNIVERSITY OF TECHNOLOGY
}

\section{Fast switching and wideband photonic beamformer with flat RF response and squintless scan performance}

\section{Citation for published version (APA):}

Raz, O., Barzilay, S., Rotman, R., \& Tur, M. (2007). Fast switching and wideband photonic beamformer with flat RF response and squintless scan performance. In Proceedings of the 2007 Conference on Optical Fiber Communication/National Fiber Optic Engineers Conference, OFC/NFOEC 2007, 25-29 march 2007, Anaheim, California (pp. OWU3-1/3). Institute of Electrical and Electronics Engineers.

https://doi.org/10.1109/OFC.2007.4348949

DOI:

10.1109/OFC.2007.4348949

Document status and date:

Published: 01/01/2007

\section{Document Version:}

Publisher's PDF, also known as Version of Record (includes final page, issue and volume numbers)

\section{Please check the document version of this publication:}

- A submitted manuscript is the version of the article upon submission and before peer-review. There can be important differences between the submitted version and the official published version of record. People interested in the research are advised to contact the author for the final version of the publication, or visit the $\mathrm{DOI}$ to the publisher's website.

- The final author version and the galley proof are versions of the publication after peer review.

- The final published version features the final layout of the paper including the volume, issue and page numbers.

Link to publication

\section{General rights}

Copyright and moral rights for the publications made accessible in the public portal are retained by the authors and/or other copyright owners and it is a condition of accessing publications that users recognise and abide by the legal requirements associated with these rights.

- Users may download and print one copy of any publication from the public portal for the purpose of private study or research.

- You may not further distribute the material or use it for any profit-making activity or commercial gain

- You may freely distribute the URL identifying the publication in the public portal.

If the publication is distributed under the terms of Article 25fa of the Dutch Copyright Act, indicated by the "Taverne" license above, please follow below link for the End User Agreement:

www.tue.nl/taverne

Take down policy

If you believe that this document breaches copyright please contact us at:

openaccess@tue.nl

providing details and we will investigate your claim. 


\title{
Fast Switching and Wideband Photonic Beamformer with Flat RF Response and Squintless Scan Performance
}

\author{
O. Raz, S. Barzilay, R. Rotman and M. Tur \\ Department of Interdisciplinary Studies, Tel Aviv University, Ramat Aviv, Tel Aviv, 69978, Israel \\ odedr@eng.tau.ac.il
}

\begin{abstract}
A wideband $(>10 \mathrm{GHz})$ beamformer, based on a photonic true-time-delay, with submicrosecond angle switching is reported. The smooth microwave transmission (ripples $\left.<0.5 \mathrm{~dB} \&<3^{\circ}\right)$ and superb uniformity among the elements $\left(<0.1 \mathrm{~dB} \&<0.5^{\circ}\right)$ result in excellent $\mathrm{RF}$ performance

(C) 2005 Optical Society of America

OSIC codes: (350.4010) Microwaves
\end{abstract}

\section{Introduction}

Photonic implementations of RF True Time Delay (TTD) [1] should prove beneficial for next generation wide bandwidth radar systems [1][5]. A photonic beamformer should have an almost distortion-less, very wideband RF transfer function between the array input port (in transmit) and each of the output ports, feeding the antenna elements. Moreover, in order for the beamformer to generate a clean spatial beam and a sharp impulse response (when the input RF pulse is phase coded, e.g., in the case of linear frequency modulation (LFM)) [6], very high degree of uniformity is required among the transfer functions of the different elements. Finally, fast angle switching is a must for high PRF systems and for Track While Scan applications.

Previously demonstrated photonic beamformers have concentrated on the time delay performance of the suggested designs [1]-[4]. However the need to maintain smooth microwave performance of each TTD element over a very wide bandwidth, and even more importantly: the necessity to maintain uniform performance among all TTD devices used in the same array, was not addressed in detail.

In this paper we present measured results for a four element photonic beamformer based on a fast tunable laser and a DWDM multiplexer, with very smooth RF response in both the $\mathrm{C}$ and $\mathrm{X}$ bands, for each of the four TTD elements. Furthermore, the variations between the RF transfer functions of the four TTD devices are minute.

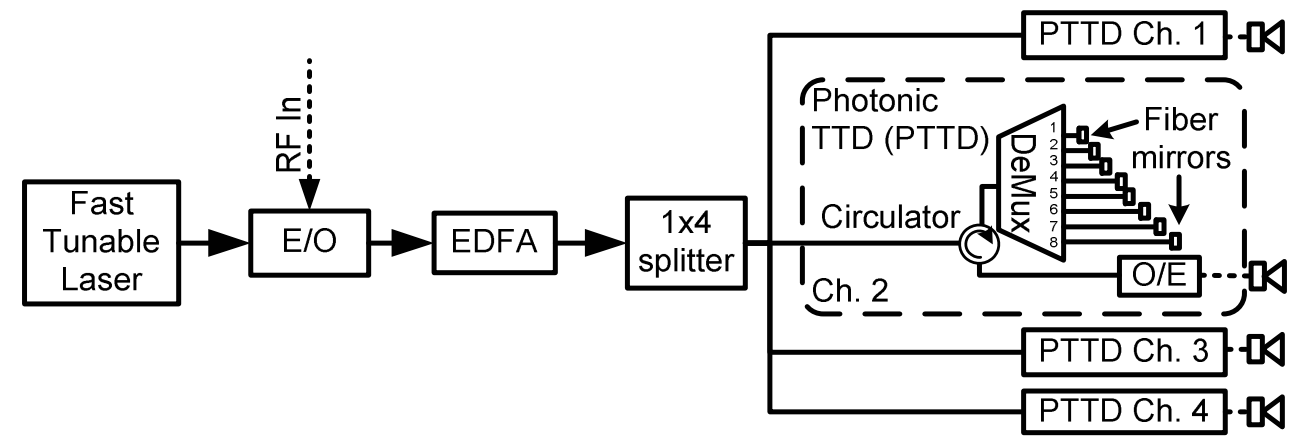

Figure 1: A four element photonic beamformer with fast angle switching

\section{The Photonic Beamformer and its Principle of Operation}

The four element (channel) beamformer is shown in Figure 2. Light coming from the fast tunable laser was double-sideband modulated by a Mach-Zehnder $\mathrm{LiNbO}_{3}$ Electrical to Optical (E/O) converter, amplified and evenly split among the four channels. While channel one consisted of a length of fiber, serving as a reference, the other three channels included a passive photonic TTD, mentioned in [4] and described in detail in [7]. An 8 channel thin film optical demultiplexer (DeMux) was used to accomplish the wavelength-controlled TTD operation, as shown in the inset in Fig. 1. The input modulated light is sent through a circulator into the DeMux, where, depending on its wavelength, it is routed to a particular output port. A different length of fiber (having a highly reflective $(\sim 100 \%)$ 
silver coated tip) is spliced to each output port of the DeMux, with a predetermined increment from port to port. Thus, the returned light emerging from the circulator into the photo receiver $(\mathrm{O} / \mathrm{E})$ experienced a dispersion-free, wavelength-controlled pure delay. Fast wavelength tuning, [8], is achieved here using a commercial tunable semiconductor laser, with a rated switching time of $200 \mathrm{nsec}$, maximum output power of $+9 \mathrm{dBm}$, and a measured RIN of less than $-150 \mathrm{~dB} / \mathrm{Hz}$.. The high output power of the laser and the EDFA optical gain compensate for the insertion loss of the Mach-Zehnder Modulator (E/O), the photonic TTD (about 5 and $7 \mathrm{~dB}$ respectively), as well as the $7 \mathrm{~dB}$ insertion loss of the splitter. All channels (excluding channel 1) have the same DeMux but different lengths of fiber are spliced to its ports. If the length increment between neighboring ports of the DeMux of channel 2 is $\Delta L$, then the corresponding length increments of channels 3 and 4 will be $2 \Delta L$ and $3 \Delta L$, respectively. If one adjusts port 1 of all TTDs to provide the same delay as the reference fiber of channel 1 , then by tuning the laser to that wavelength which goes through port 1 , one achieves a forward propagating transmitted wavefront. Tuning the laser to a different wavelength will result in a tilted wavefront. Bidirectional scanning is obtained when a middle port provides equal delay for the four channels, rather than port 1. In our beamformer $\Delta L$ was designed to give delay increments of $50 \mathrm{ps}$, and this goal was achieved to within less than $\pm 5 \mathrm{ps}$.

\section{Results}

Using an RF vector network analyzer, full RF characterization of the four separate channels has been carried out in both the $\mathrm{C}$ and $\mathrm{X}$ bands and for the $200 \mathrm{GHz}$ equally spaced eight ITU grid wavelengths from $1547.72 \mathrm{~nm}\left(\lambda_{1}\right)$ to $1558.98 \mathrm{~nm}\left(\lambda_{8}\right)$. Figure 2 shows the magnitude and phase responses in both bands after some processing, as detailed below.
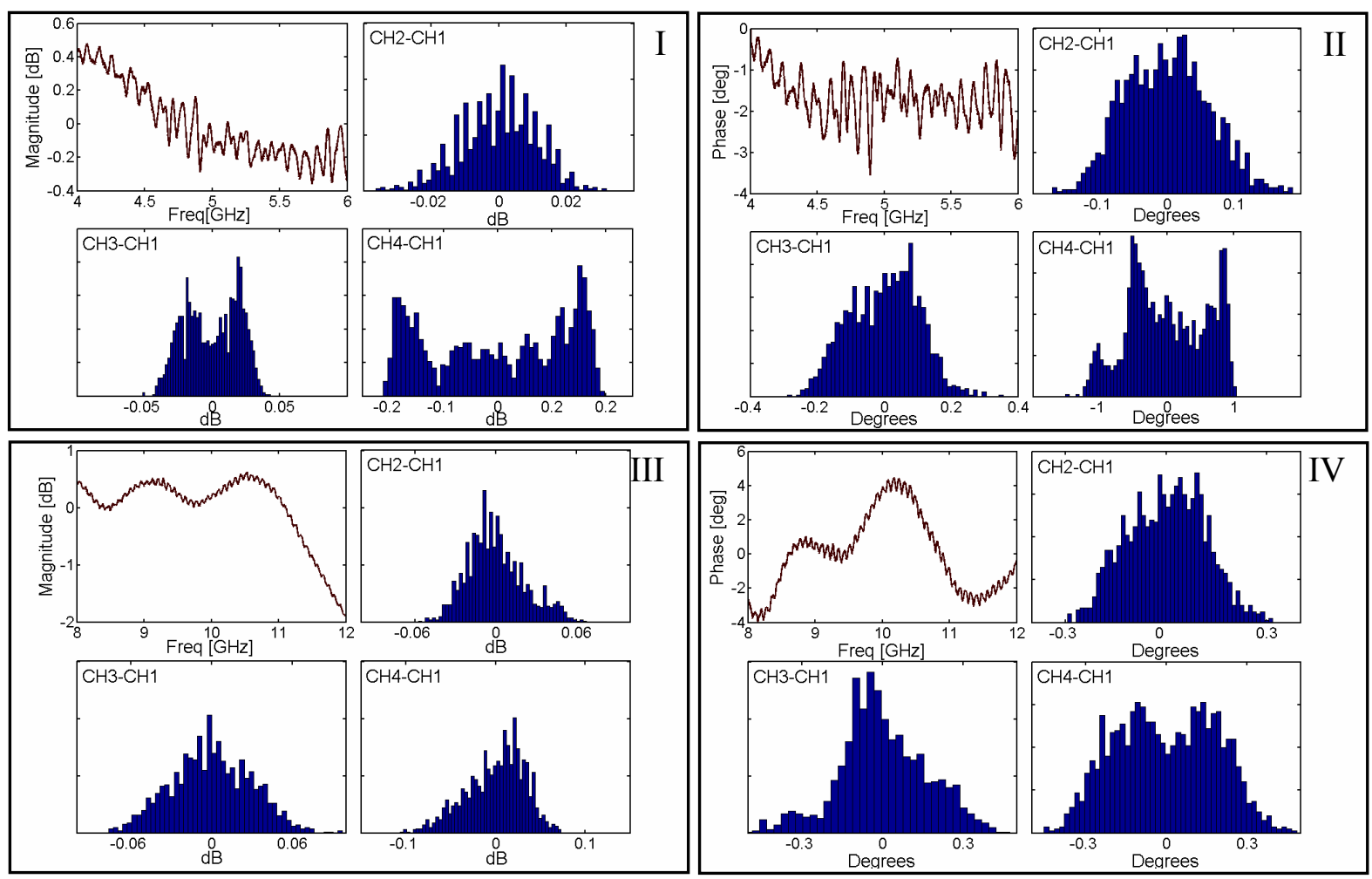

Figure 2: $\mathrm{C}$ and $\mathrm{X}$ band magnitude (I,III) and phase (II,IV) characterization results

The top left box in each of the four frames shows the magnitude or phase of the transfer function when using $\lambda_{1}$ in channel 1 (the reference channel). For each of the channels all wavelengths practically exhibited the same transfer function (up to (RF) frequency-independent loss for the magnitude and delay-related linear trend for the phase), indicating that the observed ripples originate from the $\mathrm{E} / \mathrm{O}$ and $\mathrm{O} / \mathrm{E}$ converters. The other boxes are histograms of the deviations of the transfer function of $\lambda_{1}$ of each of the other channels from the corresponding transfer function of channel 1. Again, frequency-independent loss was removed from the magnitude data, as well as linear trend from the phase data. It is seen that the worst case magnitude error between channels over any of the two bands is less than 


\section{OWU3.pdf}

$0.2 \mathrm{~dB}$. The phase response varies between the four different PTTDs by less than $1^{\circ}$. Similar performance has been observed anywhere in the $0-12 \mathrm{GHz}$ frequency range, limited from above by the bandwidth of the off-the-shelf EO converter. Such minor variations between the elements will have negligible effect on the wideband performance of the beamformer [9].

Experimentally, the tunable laser was pre-programmed to operate for $20.3 \mu \mathrm{sec}$, at each wavelength, while the LFM generator emitted a sequence of identical eight $20 \mu \mathrm{sec} 1 \mathrm{GHz}$ LFM pulses, 300nsec apart (we added $100 \mathrm{nsec}$ extra time to the specified 200nsec switching time to ensure complete wavelength settling of the laser). The LFM sequence was triggered by an electronic signal generated by the tunable laser, announcing the beginning of a new wavelength cycle. Shown in Fig. 3, are the 8 LFM pulses after detection as captured by the oscilloscope. The time gap of $300 \mathrm{nsec}$ between the pulses is barely noticeable. Evidently, each wavelength sees a slightly different insertion loss. Fig. 4 depicts the resulting impulse response. A Peak Side Lobe level (PSL) of $-37 \mathrm{dBc}$ is observed, indicating high performance of this fast tunable photonic TTD. All other wavelengths have been similarly checked, producing identical PSL results. Since under CW conditions similar PSL values were observed [7], and since there are negligible differences among the different channels, we conclude that the deviations of the measured impulse response form the ideal Hamming base curve with a PSL of $-42 \mathrm{~dB}$, is mainly due to E/O converter (whose performance can be much improved) and the fast switching does not contribute further impairment.

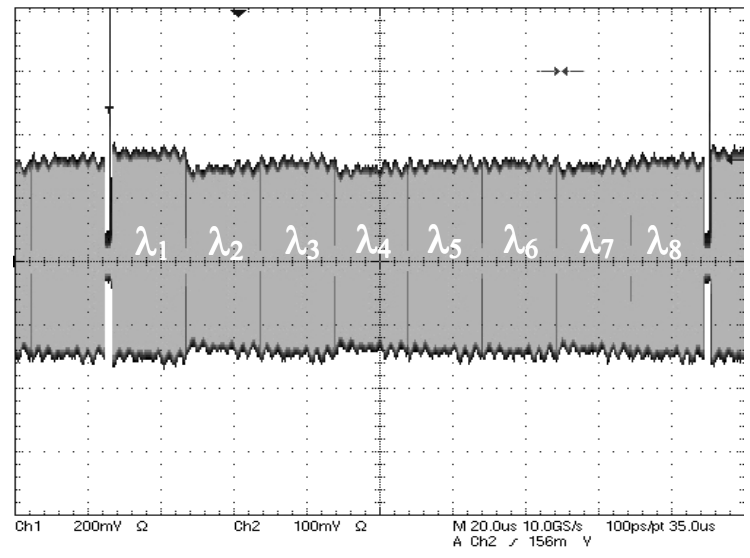

Figure 3: Oscilloscope image capture of the eight LFM pulses

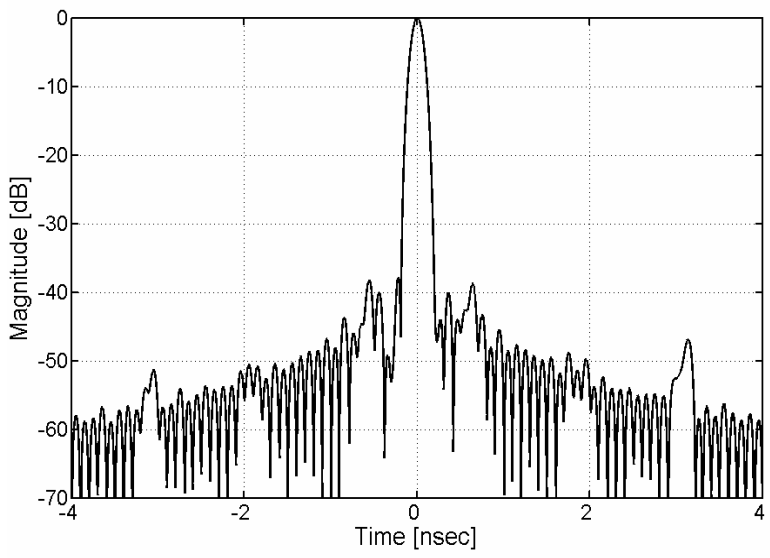

Figure 4: Processed temporal impulse response for a $1 \mathrm{GHz}$ LFM pulse

\section{Conclusion}

We have constructed and successfully demonstrated the operation of a fast switching, four element photonic true time delay beamformer. The observed low ripples in magnitude and phase of the beamformer elements (over any $1 \mathrm{GHz}$ band in the $0-\sim 12 \mathrm{GHz}$ range) enable high quality transmission of a $1 \mathrm{GHz}$ LFM pulse with very low sidelobe levels. The variations between the microwave responses of the four different elements are minute and way better than what can be currently obtained from a similar microwave TTD implementation. With proper use of optical amplification, the architecture can be extended to tens of elements, and to hundreds, when subarrays are employed [9].

\section{References}

[1] R.D. Esman, M.J. Monsana, J.L. Dexter, D.G. Cooper, "Microwave true time-delay modulator using fibre-optic dispersion", Electronics Letters, vol. 28, no.20, pp. 1905-1907, 1992

[2] J.J. Lee, R.Y. Loo, S. Livingston, V.I. Jones, J.B. Lewis, H.W. Yen, G.L. Tangonan \& M. Wechsberg, "Photonic Wideband Array Antennas", IEEE Trans. On Antenna and Propagation, Vol. 43, No. 9, 1995

[3] J.L. Corral, J. Marti, S. Regidor, J.M. Foster, R. Laming, M.J. Cole, ”Continuously variable true time-delay optical feeder for phased-array antenna employing chirped fiber grating", IEEE Trans. on MTT, vol. 45, no. 8, pp. 1531 - 1536, 1997

[4] N. A. Riza, S. Sumriddetchkajorn, "Micromechanics-based wavelength-sensitive photonic beam control architectures and applications", Applied Optics, Vol. 39, No. 6, pp. 919-932, 2000

[5] H. Zmuda, E.N. Toughlian, "Photonic aspects of modern radar", Artech House, 1994

[6] J. R. Klauder et al,"The Theory and Design of Chirp Radars", Bell System Technical Journal, no.39 pp.745-808, 1960

[7] O. Raz, R. Rotman, M. Tur, "Wavelength-Controlled Photonic True Time Delay for Wide-Band Applications", IEEE Photon. Technol. Lett, Vol. 17, no. 5, pp.1076-1078, 2005

[8] M.Y. Frankel, R.D. Esman, J.F. Weller, "Rapid Continuous Tuning”, IEEE Photon. Technol. Lett., vol. 6, no. 5, pp. 591-593, 1994

[9] R. Rotman, S. Barzilay, O. Raz, S. Rotman, M. Tur, "Wideband Antenna Patterns and Impulse Response of Broadband RF Phased Arrays with RF and Photonic Beamforming", accepted for publication in IEEE Transactions on Antennas and Propagation 